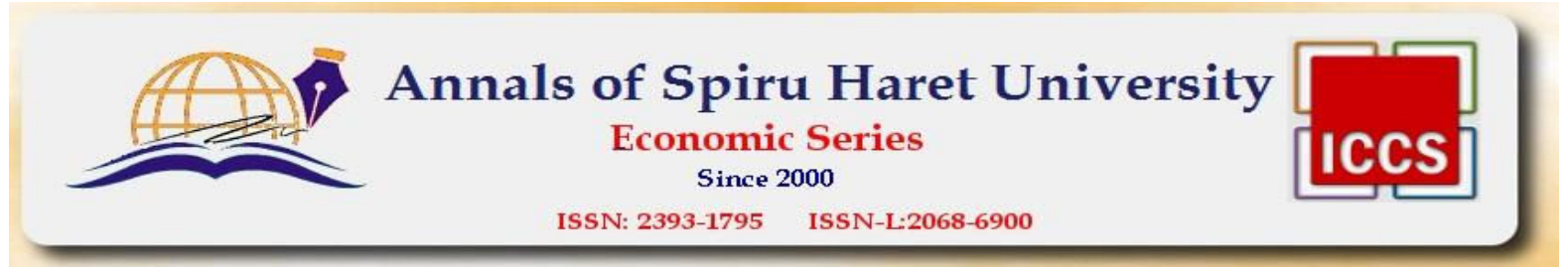

Issue 4/2016

\title{
ADAPTATION AND PROGRESS THROUGH CHANGE MANAGEMENT
}

\author{
Gabriela MEHEDINTU' ${ }^{1}$, Ana MUNTEANU ${ }^{2}$ \\ ${ }^{1}$ Technical University of Civil Engineering Bucharest, no. 122-124, Lacul Tei Bvd., \\ 020396, Bucharest, Romania, Tel.: +4021242.12.08, Fax: +4021242.07.81, Email: \\ gabriela.mehedintu06@gmail.com \\ 2"Spiru Haret" University, Faculty of Juridical, Economic \\ and Administrative Sciences Braşov, 7 Turnului Street, Braşov, Romania, \\ Tel.:+40214551062, Fax:+40268548224, Email: anamunteanu.engleza@gmail.com
}

\begin{abstract}
The technological progress, digitization and the explosion of information significantly change how individuals, the business environment, and society act, develop and add value. New, interdisciplinary approaches, constantly adapted and sustainable both at the micro and the macro levels are required. Within a company, change management is a systematic element of the strategic business process and involves the early identification of the opportunity of the employees' development, courage, commitment and flexibility; under no circumstances should it be seen as a risk and instability factor, as it may be considered in the early stages. The example presented in this article proves that the openness to change and continuous improvement develops advantages, optimizes processes and sustains long-term progress.
\end{abstract}

Keywords: change management, continuous improvement, optimization, progress.

JEL Classification: M21, O33

\section{Introduction}

This paper looks at the various definitions that change management has been given, finds some reasons why companies should use change management in order to be more efficient and presents an example which proves that the openness to change and continuous improvement develops advantages, optimizes processes and sustains long-term progress.

The technological and informational explosion, which requires new approaches useful and necessary for the individual, the company, and the society to adapt to the new trends, determines today's perpetual change.

Companies, particularly, are obliged to adapt and implement change for multiple reasons, among which [Lindinger \& Goller, 2004]:

- technological developments accelerate any company's processes; for change;

- global information networks make business processes transparent creating a certain pressure

- customers' increased expectations based on information determine new approaches to quality and services;

- sustainability is ensured only through cooperation;

- changes in international legislation require rapid adaptability.

The term 'change' is joined inevitably by the term 'development', and change management is the proactive method of managing change which brings success to the companies that integrate it into the daily agenda of the company's management [Rank \& Scheinpflug, 2010]. 

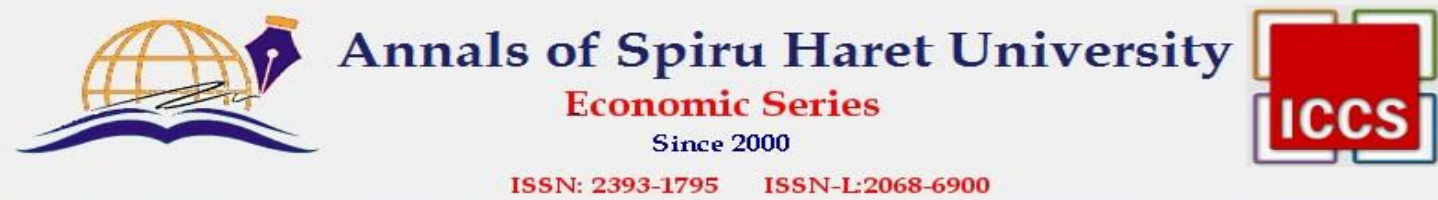

ISSN: 2393-1795 ISSN-L:2068-6900

Issue 4/2016

\section{Definitions of change management in a company in literature}

Change management has active implications in the company's adaptation and development, requires an interdisciplinary approach starting with the senior management levels, which is why the literature identifies many of its approaches.

One approach defines change management as a 'symbiosis between leadership and management'; it is an emotional approach to the issues between a company's employees and management [Friedrichsmeier \& Frühauf, 2009], because a company is managed and exists through the active involvement of the people, i.e. its main resource.

Another approach of the change management looks at it as the sum of all the conscious methods for implementing the processes that lead to change in an organization. Under this approach, change is a conscious and active action, i.e. a chosen and responsible decision [Lindinger \& Goller, 2004]. Viewed from this perspective, change management also includes the techniques for solving the staff's problems, as well as the change impact on the corporate amendments so that the desired change can be implemented effectively and efficiently [Pirker, 2007].

The economist Peter Drucker makes a difference between the terms effective and efficient, by linking effectiveness with the phrase 'do the right things' and effectiveness to 'do the things right' [Drucker, 1969]. For the organization to be sustainable and have long-term competitive advantage, managers should correctly apply both concepts.

Efficiency refers to the use of an organization's resources on long-term also in terms of cost, from the planning stage to the stabilization and control of change. The effectiveness of change management refers to two components:

- firstly, there is the question to what extent the company operates correctly the resources involved; and

- secondly, it refers to the acceptance of change and the identification of the employees with the change [Tanţău \& Bock, 2010].

\section{Change, the permanent need in the business environment}

The business environment, which is in a permanent adaptation, requires a firm to act flexibly, to recognize and accept very early the need for change and attach high importance to change management and its processes through their involvement in the strategic decision-making processes; under no circumstances should change be considered a risk factor.

Change management involves having courage, desire for transformation and a new way of looking at problems. The linear thinking and the 'homo economicus' image (the economic man - the individualist man concerned about his own needs) loses ground every day. The complexity of the new competitive environment can no longer be monitored only by summing the factors influencing the organization. The economic factors should be supplemented with other noneconomic factors, such as the employees' satisfaction [Costache, 2001].

In this regard, David Swanson, the American manager from Procter \& Gamble argues that change management must be a matter of survival [Keuper and Groten, 2007].

Among the most notable failures to adapt to change, there are:

- the Kodak case: as J. Kotter noted in a Forbes article in 2012, the success Kodak had with the photographic film made the company's management overconfident, so they didn't think of innovating anymore and adapting to the trend imposed by the digital cameras they invented;

- the Nokia case: as Haydn Shaughnessy noted in a Forbes article in 2013, Nokia did not respond actively to the trend imposed by Apple and Android on the smartphone market, being reluctant to the advantages offered by the new touchscreen phones on the market. They only tried to improve their own system: Symbian OS, which did not bring anything new. It was overtaken in 2011 by Windows, but it was already too late for the company to be able to regain the strength and the market share it originally had. 


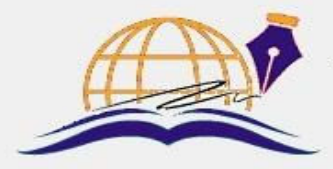

Annals of Spiru Haret University

Economic Series

Since 2000

ISSN: 2393-1795 ISSN-L:2068-6900

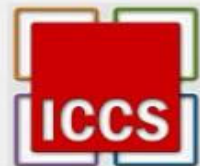

Issue 4/2016

Change management has as main objective the successful implementation of change, following the established plan and obtaining the following advantages [Pirker, 2007]:

- understanding the needs for change;

- preparing for impact;

- motivation for the common goal;

- controlling the expectations;

- acceptance of the management team and its inclusion in the process;

- employees' involvement.

The essential factors of change should be used in such a balanced way that the company optimizes the internal processes and survives on a long-term the dynamic environment it is located in.

\section{Adaptation and exploitation of the technological progress}

A company is sustainable when it adapts and progresses, when it has well-defined strategies, when it converts the internal and external dynamics into advantages. This approach requires constant learning, flexibility, a strong organizational culture and focus on the employees and on a comfortable working environment, properly adapted to the working needs and modern security.

A good example of a strategic decision which leverages technological progress and adapts the company to the new beneficial trends is a company that owns an office building, built in 1966-1970, with just one floor, with a total area of 919 square meters and a used floor area of 797 sqm, where a total of 56 employees work 40 hours per week.

The building has the following individual technical features:

- electrical installation;

- gas central heating - $93 \mathrm{~kW}$ heat output;

- radio burglar alarm system with 32 detectors;

- air conditioners - 12,000 BTU;

- water supply and sanitation systems.

The utilities consumption for the years 2014 and 2015 are presented in the following chart:

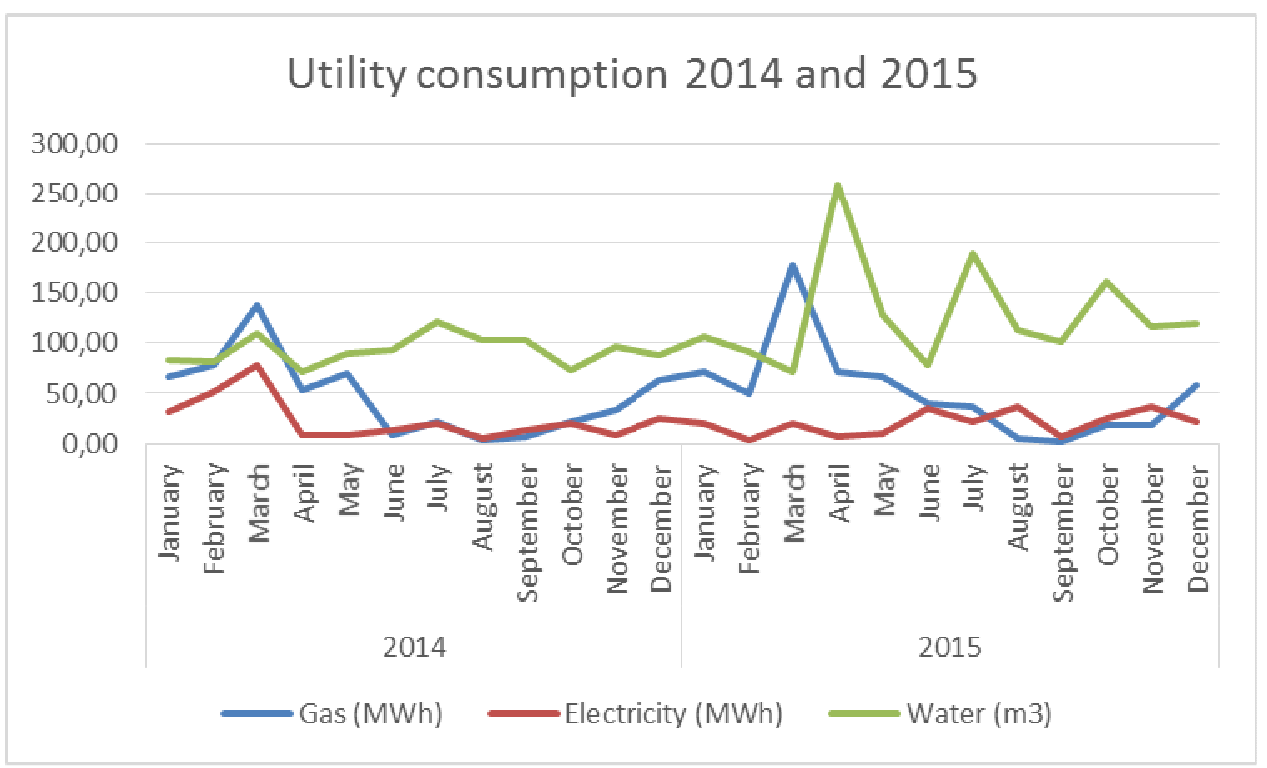

Figure no. 1. Utility consumption 2014 and 2015

Source: own elaboration 

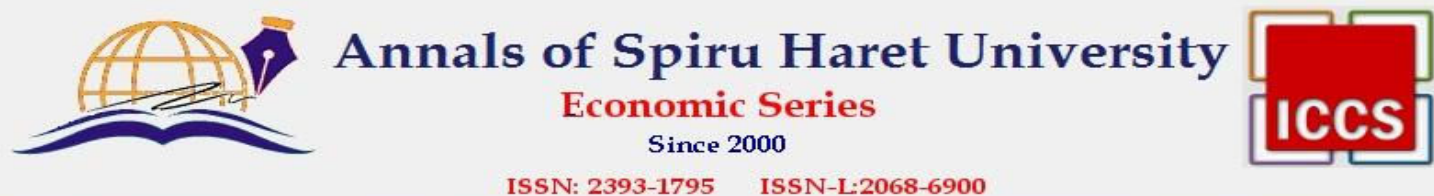

ISSN: 2393-1795 ISSN-L:2068-6900

Issue 4/2016

Since there is a need and a strategic tendency to optimize the consumption of utilities because of the environmental, social and economic impact that they have and because there are already modern technologies that can meet the companies that want to develop in a sustainable way, the analyzed company decides to implement the change of the existing technologies, introducing an integrated building management system (BMS), which presents a series of economic and technical advantages, among which:

- it increases the indwellers' comfort;

- it increases the indwellers' satisfaction;

- it increases labour productivity;

- it has a more effective control over the total occupied space;

- it reduces the $\mathrm{CO}_{2}$ emissions;

- it can monitor the energy consumption;

- it can monitor the activity around the building;

- it can identify and alert timely the emergency situations;

- it can monitor and control the building in a flexible way.

The literature and the implementation of such systems prove that such a change in a company can optimize the costs and consumption by about $30 \%$.

In our example, the company tries to constantly adapt to the internal and external environment through a culture of change and through the use of the tools of continuous improvement, and the optimization of the working processes.

Rank and Scheinpflug support Vahns' theory that defines four areas which identify the need for change [Baetge et al, 2007]:

- Strategy: building the strategic competitive advantage by exploiting the successful potential of the company. The company from our example uses continuous improvement processes in order to obtain a high quality working environment for its employees and to increase productivity.

- Organizational culture plays an important role when a change strategy of the employee's behaviour and thinking is desired, because it motivates the employee through appropriate communication structures.

- Technology: change at the technological level in an organization is usually linked to the organization's desire to adapt to the new.

- Organization: by organization we understand the organizational and organizing structure. By changing one of these structures, a change (restructuring or adaptation) also occurs at the organization's level. For example, in order to reduce the utility costs and increase the employees' satisfaction and productivity, the management uses continuous improvement processes that affect both the organizational structure and the organizing one.

Within the change management an important role belongs to the employee. The progress is supported by the long-term policy which requires liability to employees and society. Thus, among the important objectives of the company there are the qualitative development and the employee's satisfaction. For these to be achieved, it is promoted an optimum, attractive working environment, adapted to the European working requirements and standards, motivating employees through open communication with them in order to stimulate the employee during the daily work.

Responsible for developing a professional working environment, modern and economical, is the facility manager, who is empowered to adapt the building to the modern technological innovations in order to meet the employees' expectations. That is why, in the above mentioned example, the manager's aim is to modernize the building with BMS. The implementation of change lasts 5 months. 


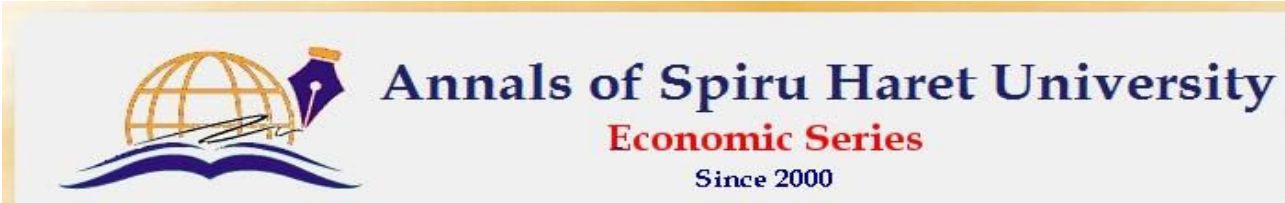

ISSN: 2393-1795 ISSN-L:2068-6900

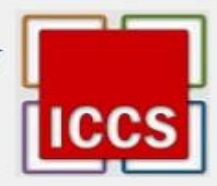

Issue 4/2016

\section{Identifying the employees participating to change}

In terms of change management and implementation, it is necessary to know the nature of change, the processes and the parties involved, their roles, respectively. There are five categories of participants to change that fulfil different roles [Conner \& Clements, 1999] (see Fig. 2):

- Sponsor: the one who legitimizes the change and shapes the frame. For the company we took as an example, this role is taken by the company's facility manager. He is the one who identified the need for change, starting from the technological progress existing in the market and from the need to adapt and optimize the working environment in order to increase the safety of the building, the employees' productivity and reduce the cost of utilities in the medium and long term. He filed an application to change following a detailed analysis and gave it to the company's general manager, mentioning the technical, social, environmental and economic advantages brought by the implementation of the change.

- Change leaders are those who want to introduce change, but cannot do this legitimately. They are part of the project team, confirm and support the change, and are the contact people for specific questions. In our example, they are represented by the two colleagues: the technical manager and the economist, who participated in the change implementing study.

- Change agents are responsible for the actual execution of change. They evaluate the problems, develop the plans and implement the change effectively. Therefore, they are the direct contacts, being the intermediate people between the sponsors and the stakeholders; they are responsible for producing the change, control the sponsors' commitment and handle the data collection on the state of implementation of the instrument and the beneficiaries' response to change. They help to support the beneficiaries, as well as their motivation and involvement, and make an important contribution in achieving change. In the company from our example, the change agents are two employees of the facility management department.

- Targets are directly affected by the change. They must be informed and must understand the need for change and they have to accept it. A change is successful only to the extent that the beneficiaries are aware, willing, and accept the change. They are represented by all the company's employees.

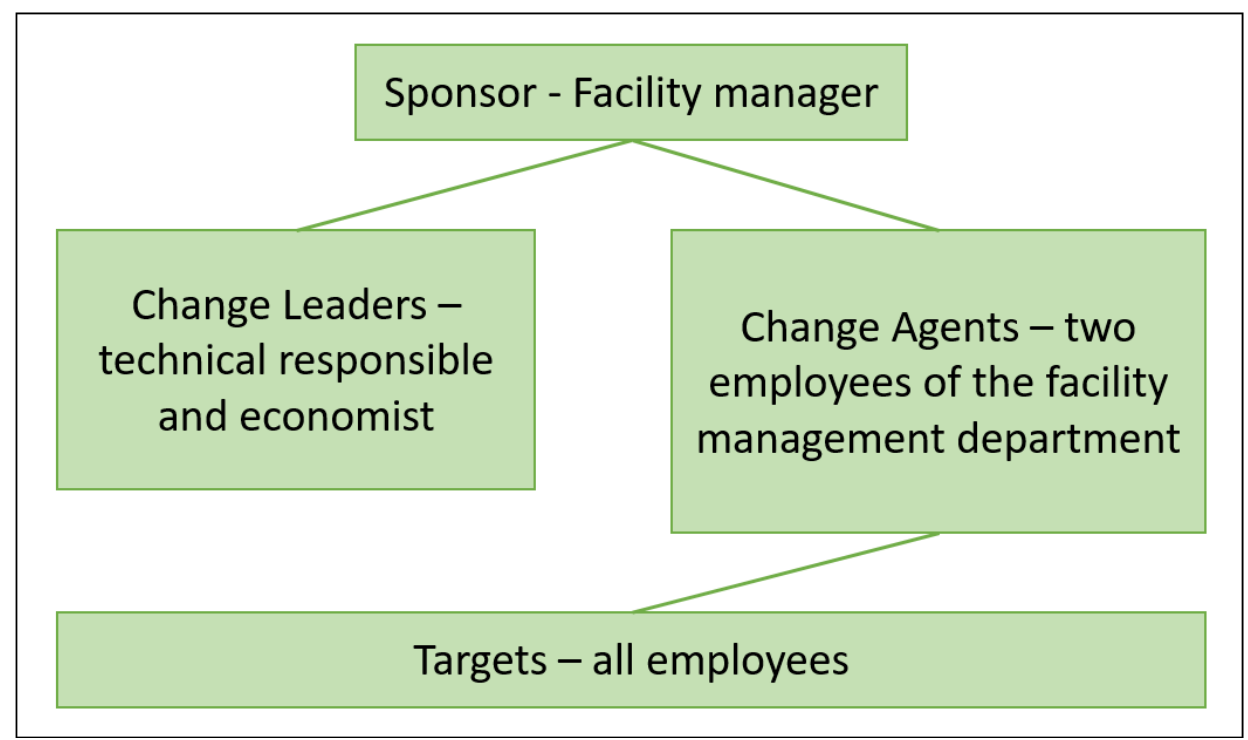



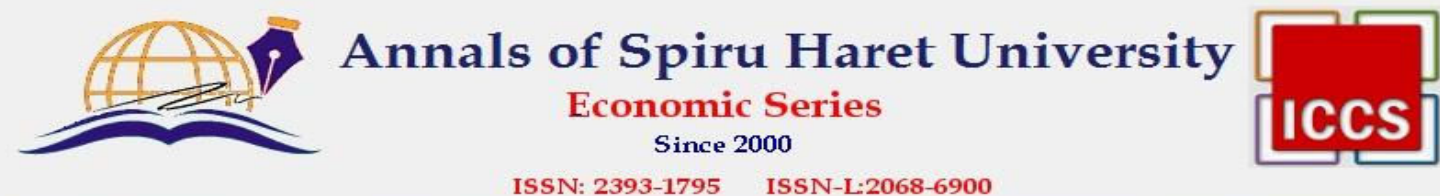

ISSN: 2393-1795 ISSN-L:2068-6900

Issue 4/2016

Figure no. 2. Participants to Change

Source: own elaboration based on Conner \& Clements, 1999

\section{Adaptation and acceptance by communicating change}

The key success factor of change management that can prevent and overcome resistance is communication. To have guaranteed success, all kinds of interpersonal communication, regardless of the direction and level of management, will be used in all phases of change implementation. Communication can be formal, when it occurs during meetings, or by e-mail. For the company shown as an example, the change was officially communicated by weekly meetings between the change agents and the management of the human resources department, as well as by quarterly meetings with the top management of the company. There were also image-based communications, which exert a strong influence on the employees' behaviour, because images have a strong emotional component.

Seminars were organized with all the employees in order to inform, clarify, persuade, engage and lead to action [Rank \& Scheinpflug, 2010]. Direct talks between the change agents and the beneficiaries were facilitated, this communication being more informal, as the company works with a small number of employees.

\section{Resistance to change}

Change management and resistance are two interdependent components because, as long as there is a situation of balance, resistance does not intervene, but when it comes to change, resistance to change comes because man feels he is losing control of the situation. The reasons that cause resistance to change are numerous: fear, reluctance to learning, lack of self-confidence, convenience.

Although the X company has developed a culture of change, it is led by people whose individual behaviours can hamper work processes or even the functioning of the organization (for example, the lack of communication and information, limited time, high volume of work, insufficient knowledge). The human resource is a decider entity that may affect the implementation of change through their perceptions and actions. People's capabilities to respond to change are different. Implementing change is easier in teams made up of proactive and cooperative people than in those made up of reluctant people.

In the given example, the resistance came mainly from the beneficiaries whose behaviour has followed the general reaction to the change, represented in Figure no. 4 [Kostka \& Monch, 2009]:

- Shock/surprise: unexpected circumstances arise. Beneficiaries have refused to attend the information seminars.

- Refusal/denial: the person is convinced that change is not necessary. Managers do not see change as a factor of progress, considering the current situation optimum and still refuse to attend the information seminars. They consider that the effort is too big and the five-month change implementation period causes major delays in their current work.

- Rational understanding: characterized by recognizing the need for change. The facility manager discusses face-to-face with the beneficiaries who understand the need for change but still do not accept it.

- Emotional acceptance: the behaviour changes towards adopting the new conditions. The employees begin to accept change and be aware of the advantages of the new system to be implemented.

- Exercising, learning: the emotional acceptance triggers the desire of a learning process, which can get a positive behaviour. Following the seminars, the beneficiaries adopt a positive behaviour, becoming open to the new. 


\section{2 \\ Annals of Spiru Haret University \\ Economic Series \\ Since 2000 \\ ISSN: 2393-1795 ISSN-L:2068-6900}

ICCS

Issue 4/2016

- Realisation: through the learning process, more and more information are acquired that determine the awareness of the situation. Managers are now convinced of the need for change and expect a positive result of the implementation.

- Integration: the new behaviour is fully integrated, so they are considered natural. The use of BMS starts.

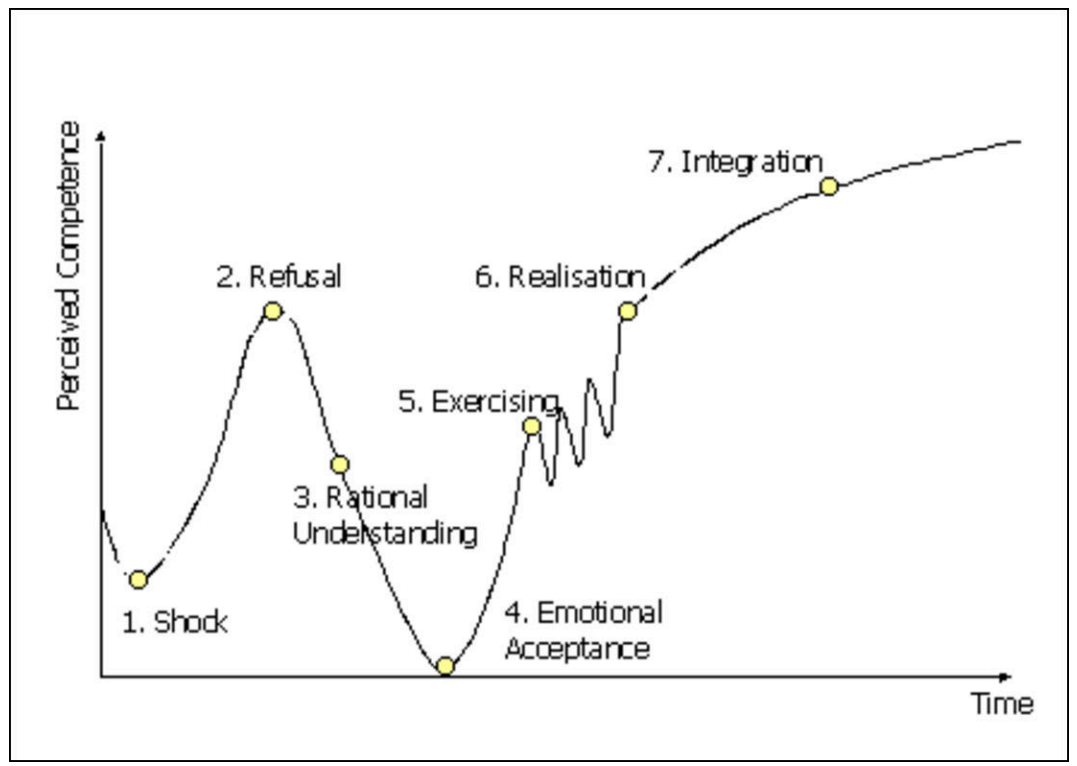

Figure no. 3. Phases of the change process

Source: Claudia Kostka and Annette Monch, Change Management. 7 Methoden für die Gestaltung von Veranderungsprozessen (München: Carl Hanser, 2009), p. 14

The successful implementation of BMS is equally visible in this case, as in other similar cases. The utility consumptions decrease on average by $35 \%$ and evens according to the graph shown in Figure no. 4. Furthermore, the employees' satisfaction increases due to the comfort of the workplace offered by the new technology 

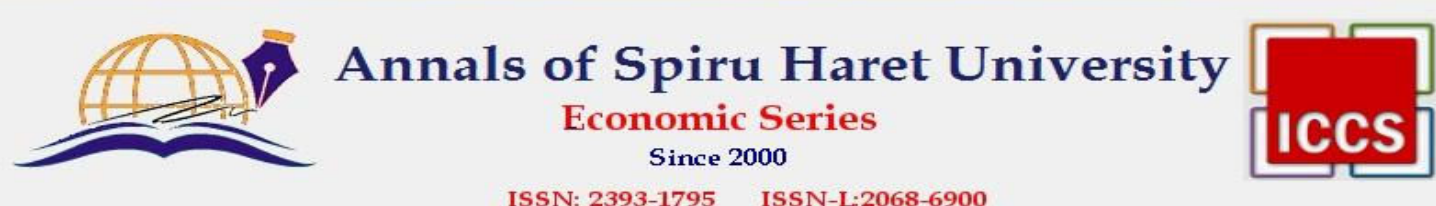

ISSN: 2393-1795 ISSN-L:2068-6900

\section{Issue 4/2016}

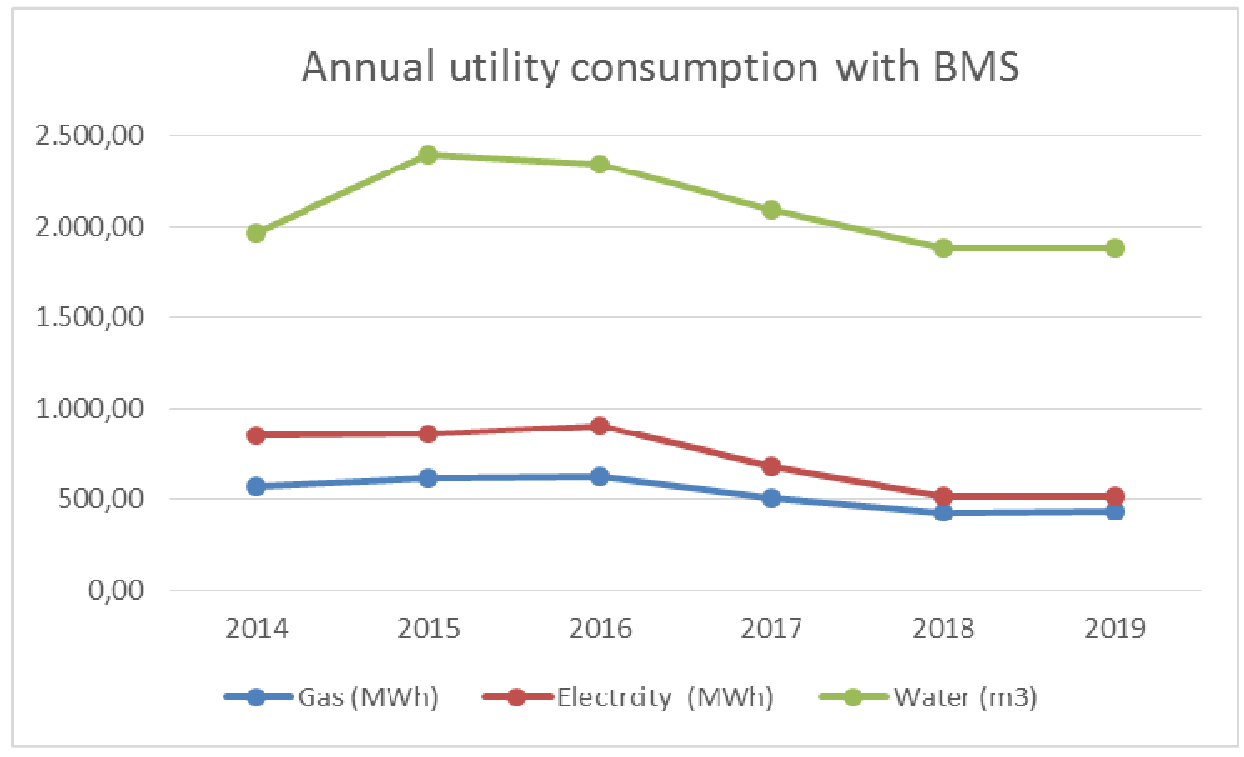

Figure no. 4. Annual utility consumption with BMS

Source: own elaboration

\section{Conclusions}

The example of implementing change in a company in order to optimize its processes is a representative one for today's dynamics, when technology plays an important role and the adaptation to the new trends is essential for a company that wants to be sustainable. The attention directed towards the employee, the environment and the economic effects proves the companies' strategic approach that wants to progress, to develop.

Change management should be a key point in the top management's decisions, in a company's culture and in all the employees' thinking. Only through flexibility, positive response to the current developments and a proactive attitude can a company progress and develop in a sustainable way.

\section{References}

1. Baetge, J., Schewe, G., Schulz, R., \& Solmecke, H., "Unternehmenskultur und Unternehmenserfolg: Stand der empirischen Forschung und Konsequenzen für die Entwicklung eines Messkonzeptes", Journal für Betriebswirtschaft, Vol. 57, Nr. 3-4 (2007).

2. Conner, D.R., and Clements, E., "Die strategischen und operativen Gestaltungsfaktoren für ein erfolgreiches Implementieren". In Werkzeuge für das Change Management. Prozesse erfolgreich optimieren und implementieren, ed. Spalink, H. (Frankfurt am Main: Frankfurter Allgemeine Zeitung, 1999).

3. Costache, S., Diç̧ionar de economie (Dictionary of Economics) (Bucureşti: Editura Economică, 2001).

4. Drucker, P., "Management's new role". Harvard Business Review, (November-December 1969), pp. 49-54.

5. Friedrichsmeier, H., and Frühauf, H., Durch Veränderung zum Erfolg (Wien: Linde, 2009).

6. Keuper, F., and Groten, H., Nachhaltiges Change Management. Interdisziplinäre Fallbeispiele und Perspektiven (Wiesbaden: Gabler, 2007). 

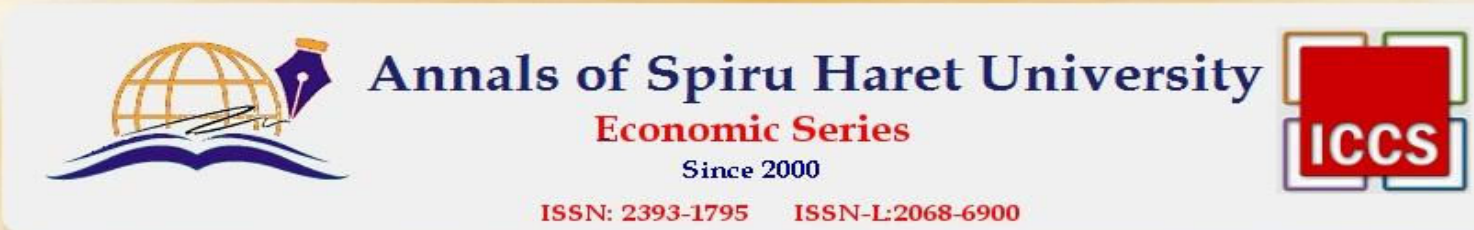

ISSN: 2393-1795 ISSN-L:2068-690

Issue 4/2016

7. Kostka, Claudia, and Monch, Annette, Change Management. 7 Methoden für die Gestaltung von Veranderungsprozessen (4th ed.) (München: Carl Hanser, 2009).

8. Kotter, J., "Barriers to Change: The Real Reason behind the Kodak Downfall", Forbes, May 2, 2012, accessed November 15, 2016, http://www.forbes.com/sites/johnkotter/2012/05/02/barriers-tochange-the-real-reason-behind-the-kodak-downfall/\#96011e536985.

9. Lindinger, Ch., and Goller, Ina, Change Management leicht gemacht: heute hier, morgen dort? (Frankfurt am Main: Readline Wirtschaft, 2004).

10. Pirker, F., "Strategy follows Change versus Change follows Strategy". In Nachhaltiges Change Management. Interdisziplinäre Fallbeispiele und Perspektiven, ed. Keuper, F., and Groten, H., (Wiesbaden: Gabler, 2007), pp. 3-30.

11. Rank, S., and Scheinpflug, Rita (Eds.), Change Management in der Praxis. Beispiele, Methoden, Instrumente. (Berlin: Erich Schmidt, 2010).

12. Shaughnessy, Haydn, "Apple's Rise and Nokia's Fall Highlight Platform Strategy Essentials", Forbes, March 8, 2013, accessed November 15, 2016, http://www.forbes.com/sites/haydnshaughnessy/2013/03/08/apples-rise-and-nokias-fall-highlightplatform-strategy-essentials/\#f87e6de4de2a.

13. Tanţău, A.D., and Bock, Jürgen, Strategisches Management. Strategische Instrumente für Zentral - und Osteuropa (Bucureşti: Uranus, 2010). 